University of Nebraska - Lincoln

DigitalCommons@University of Nebraska - Lincoln

$5-11-2005$

\title{
Cooperative effects in two-dimensional ring-like networks of three-center hydrogen bonding interactions
}

\author{
Ruben D. Parra \\ DePaul University, rparra1@depaul.edu
}

Satya S. Bulusu

University of Nebraska-Lincoln, sbulusu@iiti.ac.in

Xiao Cheng Zeng

University of Nebraska-Lincoln, xzeng1@unl.edu

Part of the Chemistry Commons

Parra, Ruben D.; Bulusu, Satya S.; and Zeng, Xiao Cheng, "Cooperative effects in two-dimensional ring-like networks of three-center hydrogen bonding interactions" (2005). Xiao Cheng Zeng Publications. 21. https://digitalcommons.unl.edu/chemzeng/21

This Article is brought to you for free and open access by the Published Research - Department of Chemistry at DigitalCommons@University of Nebraska - Lincoln. It has been accepted for inclusion in Xiao Cheng Zeng Publications by an authorized administrator of DigitalCommons@University of Nebraska - Lincoln. 


\title{
Cooperative effects in two-dimensional ring-like networks of three-center hydrogen bonding interactions
}

\author{
Rubén D. Parra ${ }^{a)}$ \\ Department of Chemistry, DePaul University, Chicago, Illinois 60614 \\ Satya Bulusu and X. C. Zeng \\ Department of Chemistry, University of Nebraska-Lincoln, Lincoln, Nebraska 68588
}

(Received 13 December 2004; accepted 28 February 2005; published online 11 May 2005)

\begin{abstract}
Cooperative effects in two-dimensional cyclic networks containing intermolecular three-centered hydrogen bonding interactions of the type $\mathrm{H}_{1} \ldots \mathrm{A} \ldots \mathrm{H}_{2}$ are investigated by means of ab intio molecular orbital and density functional theory calculations. Ring-like clusters consisting of three and up to nine monomers of the cis-cis isomer of carbonic acid $\mathrm{H}_{2} \mathrm{CO}_{3}$ are used as basic models, where each unit acts simultaneously as a double hydrogen-bond donor and double hydrogen-bond acceptor. Cooperative effects based on binding energies are evident for $\left(\mathrm{H}_{2} \mathrm{CO}_{3}\right)_{n}$, where $n$ goes from 2 to 9. Thus, the ZPVE-corrected dissociation energy per bifurcated hydrogen bond increases from $11.52 \mathrm{kcal} / \mathrm{mol}$ in the dimer to $20.42 \mathrm{kcal} / \mathrm{mol}$ in the nonamer, i.e., a $77 \%$ cooperative enhancement. Cooperative effects are also manifested in such indicators as geometries, and vibrational frequencies and intensities. The natural bond orbital analysis method is used to rationalize the results in terms of the substantial charge delocalization taking place in the cyclic clusters. Cooperativity seems close to reaching an asymptotic limit in the largest ring considered, n=9. () 2005 American Institute of Physics. [DOI: 10.1063/1.1895713]
\end{abstract}

\section{INTRODUCTION}

Three-centered hydrogen bonds are commonly found in systems containing the $\mathrm{O}-\mathrm{H} \ldots \mathrm{O}$ and $\mathrm{N}-\mathrm{H}$... O hydrogen bonding structures, as well as the $\mathrm{C}-\mathrm{H} \ldots \mathrm{O} / \mathrm{N}$ patterns. These three-centered hydrogen bonds occur frequently in solid-state structures ${ }^{1-5}$ and also in biologically relevant molecules. ${ }^{6-9}$ An array of interlinked three-center hydrogen bonds is expected to exhibit cooperative enhancement just as it is observed in regular two-center hydrogen-bond arrays. ${ }^{10-13}$ Considerable attention has been given to the study of cooperative effects in molecular clusters containing conventional two-center $\mathrm{H}$ bonds. ${ }^{10-36}$ For example, some researchers have investigated the cooperative effects of hydrogen-bonding chains. ${ }^{25}$ King and Weinhold ${ }^{26}$ showed that even relatively weak proton donors such as $\mathrm{HCN}$ could present robust cooperative effects in large linear $(\mathrm{HCN})_{n}$ clusters. Suhai ${ }^{27}$ carried out $a b$ initio crystal orbital calculations on quasi-one-dimensional, infinite periodic lattice of water molecules as a first step to model cooperative effects in various modifications of ice. Ludwig et al. ${ }^{28}$ found strong cooperative effects in linear clusters of trans$\mathrm{N}$-methylacetamide; these authors also studied the hydrogen bonding of liquid $N$-methylacetamide using the quantum cluster equilibrium methodology and suggested the possibility of extending this methodology to a much broader spectrum of H-bonded liquids. Guo et al. ${ }^{29}$ investigated manybody effects in systems of peptide H-bonded networks; an encouraging conclusion from this work is that polarizable

\footnotetext{
a) Author to whom correspondence should be addressed. Electronic mail: rparra1@depaul.edu
}

molecular mechanics in combination with ab initio and density functional methods may be useful for studying protein structures, thanks in part to the ability of a polarizable molecular mechanics procedure to recover a major portion of cooperative effects. Dannenberg et al. ${ }^{30}$ reported an unusually high degree of cooperativity for hydrogen-bonding chains of formamide molecules and its implications for protein-folding models. Guo et al. ${ }^{31}$ investigated the role of cooperativity in the formation of $\beta$ structures in proteins without side-chain interactions. Dupré et al. ${ }^{32,33}$ conducted energetic and topological analyses of cooperative $\pi \mathrm{H}$ - and $\sigma \mathrm{H}$-bonding interactions in complexes of either one or two water molecules with ethene, propene, or allyl alcohol. The relevance of their work is discussed in terms of the elucidation of the structural/functional relationships that contribute to the signaling properties of sphingolipids. Recently, Kobko and Dannemberg ${ }^{34}$ discussed the implications of the cooperativity in chains of formamide molecules for peptide vibrational spectra. It is found that cooperativity in the H-bonded chains of formamide molecules gives rise to through $\mathrm{H}$-bonding coupling of the $\mathrm{C}=\mathrm{O}$ stretches which are stronger than the through covalent bond coupling of the corresponding $\mathrm{C}=\mathrm{O}$ stretches in polyglycines with the amide groups connected only by covalent bonds. Kar and Scheiner ${ }^{35}$ have just recently conducted a comparative study of the cooperativity in $\mathrm{C}-\mathrm{H} \ldots \mathrm{O}$ and $\mathrm{O}-\mathrm{H} . . . \mathrm{O}$ hydrogen bonds. This work presents the rather interesting result that the cooperativity of $\mathrm{O}-\mathrm{H} \ldots \mathrm{O}$ and $\mathrm{C}-\mathrm{H} . . . \mathrm{O}$ bonds is similar; although solvent effects, represented by a continuum with a dielectric constant, result in reduced cooperativity in all systems.

Cooperativity effects in bifurcated $\mathrm{H}$ bonds, however, 
have been much less investigated. Recent studies have discussed cooperativity effects in terms of the two-center components of the bifurcated $\mathrm{H}$ bond. These studies support the notion that intermolecular bifurcated $\mathrm{H}$-bond formation is a process that gives rise to negative cooperative effects. ${ }^{36,37}$ For intramolecular bifurcated $\mathrm{H}$ bonds, examples of positive and negative cooperative effects have been reported. ${ }^{38-40}$ The importance of resonance-assisted hydrogen bonding (RAHB) in bifurcated hydrogen bonds was recently pointed out by Rybarczyk-Pirek et $a l .{ }^{41}$ for the crystal structures of some new phosphorochromone derivatives. These researchers applied the theory of atoms in molecules ${ }^{42}$ to some model systems and found that although bifurcated $\mathrm{H}$ bonds are rather weak in their model systems, the presence of intramolecular RAHB strengthens the bifurcated H-bond interactions. Few studies of cooperativity effects in chains of bifurcated $\mathrm{H}$ bonds have been reported. Masunov and Dannenberg ${ }^{43}$ investigated one-dimensional hydrogen-bonding aggregates, chains and ribbons, of urea and thiourea; these authors found the cooperative interactions for the urea and thiourea chains to be similar, whereas the cooperative interactions for both ribbons were found to be negligible. Dong et $a l .{ }^{44}$ reported the first experimental determination of the carbonyl ${ }^{17} \mathrm{O}$ electric-field-gradient tensor and chemical-shift tensor; the strong hydrogen-bonding effects on these quantities were studied by systematically modeling the H-bond network in crystalline urea with several molecular clusters including bifurcated and other multicenter $\mathrm{H}$ bonds. The fundamental role of bifurcated $\mathrm{H}$ bonds in proteins, DNA crystal structures, and other biologically relevant systems has been amply demonstrated. ${ }^{45,46}$ For example, parallel and antiparallel $\beta$ sheets have been shown to contain a network of bifurcated $\mathrm{H}$ bonds where each carbonyl $\mathrm{O}$ atom accepts a pair of $\mathrm{H}$ bonds, one from a peptide $\mathrm{N}-\mathrm{H}$ and one from a $\mathrm{C}_{\alpha}-\mathrm{H}$ group of the preceding residue. ${ }^{46}$

In this paper, we report the cooperative effects in a chain of bifurcated $\mathrm{H}$ bonds. Two types of bifurcated H-bond interactions can be distinguished: (a) one that involves a hydrogen atom and two acceptor atoms (denoted $\mathrm{A}_{1} \mathrm{HA}_{2}$ ), and (b) one that involves one acceptor atom and two hydrogen atoms (denoted $\mathrm{H}_{1} \mathrm{AH}_{2}$ ). Recently, we reported strong cooperative effects in one-dimensional chains of three centered hydrogen bonding interactions of the former type, using onedimensional chains of the trans-trans conformer of the diformamide molecule. ${ }^{47}$ Cooperative effects in onedimensional aggregates of three-centered $\mathrm{H}$ bonding of the $\mathrm{H}_{1} \mathrm{AH}_{2}$ type have been studied on chains and ribbons of urea and thiourea using various $a b$ initio and semiempirical methods. ${ }^{43}$ In this work, we investigate the degree of cooperativity in two-dimensional ring-like structures containing three-centered $\mathrm{H}$ bonding with one acceptor and two donors $\left(\mathrm{H}_{1} \mathrm{AH}_{2}\right)$. In a ring-like structure, a proton-donor unit acts simultaneously as a proton acceptor unit. As a basic motif, we have conveniently chosen the cis-cis conformation of carbonic acid, $\mathrm{H}_{2} \mathrm{CO}_{3}$. It should be mentioned that a single molecule of a carbonic acid can exist in three different minimum-energy conformations. ${ }^{48-55}$ The most stable conformations is the trans-trans isomer, followed by the cistrans and cis-cis forms. Previous ab initio studies on the dimer of carbonic acid, with each monomer in its most stable trans-trans conformation, show that this dimer is remarkably stable. ${ }^{52}$ Density functional calculations on carbonic acid clusters of up to five units show that the most stable clusters are linear, H-bonded analogs of the dimer with trans-trans orientation. ${ }^{53}$ Although the cis-cis conformation is about $10 \mathrm{kcal} / \mathrm{mol}$ less stable than the trans-trans isomer, it is nonetheless a very suitable model system for the formation of cyclic clusters of varying size that are stabilized by a network of three-centered $\mathrm{H}$-bonding interactions. The extent of this stabilization is a reflection of the cooperative nature of the $\mathrm{H}$ bonds. In this work, we report the existence and degree of cooperativity associated with such carbonic acid rings, $\left(\mathrm{H}_{2} \mathrm{CO}_{3}\right)_{n}$, of size ranging from $n=3$ to $n=9$.

\section{METHODOLOGY}

All computations were carried out using the GAUSSIAN 03 program. ${ }^{56}$ The geometries for all $\left(\mathrm{H}_{2} \mathrm{CO}_{3}\right)_{n}$ clusters from $n=1$ to $n=9$ were fully optimized with subsequent frequency calculations using the 6-311+ $\mathrm{G}(d)$ basis set and the B3LYP variant of density functional theory (DFT) ${ }^{57,58}$ The DFT method has been extensively used in studies of $\mathrm{H}$-bonded clusters and tested against MP2, MP4, and G2 ab initio calculations. ${ }^{59}$ It has been found that the B3LYP H-bonding geometries are in very good agreement with MP2 geometries. ${ }^{60-65}$ Geometry optimizations were performed without any symmetry constraints, and using the Opt $=$ Tight convergence option which is usually necessary to guarantee reasonable convergence and reliability of calculated frequencies. Geometries were not optimized, however, on the counterpoise-corrected (CP) surface. ${ }^{66}$ By correcting for the nonphysical attraction due to BSSE, CP-corrected geometries are expected to result in H-bond separations that are larger than those obtained by optimization in the uncorrected surface. ${ }^{67,68}$ It has also been pointed out that the interaction energies of $\mathrm{CP}$-corrected optimized dimers are more negative, before vibrational corrections, and that the H-bonding stretching vibrations decrease in all cases. Although geometries were not corrected for BSSE, the interaction energies obtained at the MP2 level with the 6-31 $+\mathrm{G}(d), 6-31+\mathrm{G}(d, p)$, and $6-311++\mathrm{G}(2 d, 2 p)$ basis sets were corrected $a$ posteriori using the counterpoise method. ${ }^{66}$ The BSSE-corrected energies were determined by means of

$$
\Delta E=E_{n}-\sum_{i}^{n} E_{i}
$$

where $E_{n}$ is the total energy of the cluster of size $n$, and $E_{i}$ is the energy of the individual monomers, in the cluster geometry, calculated using all the basis set of the cluster. The MP2 correlation method was used in consideration of the results presented by Novoa and Sosa ${ }^{61}$ suggesting that this method provides a better description of the energetics of H-bonded complexes than density functional methods. Natural bond order (NBO) analysis was performed at the $\mathrm{HF} / 6-311+$ $+\mathrm{G}(d, p)$ level on the B3LYP/6-311+ $\mathrm{G}(d)$ optimized geometries. 


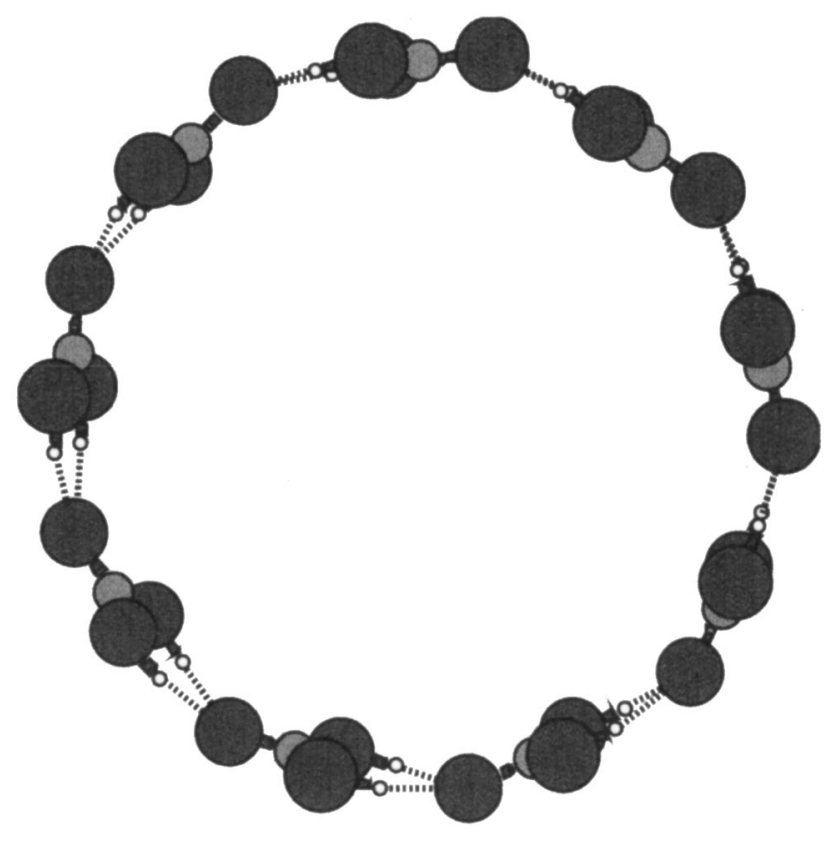

FIG. 1. B3LYP/6-311+G(d) optimized geometry of the ring-like clusters of carbonic acid containing nine monomers.

\section{MODEL SYSTEMS}

The two-dimensional ring-like network of hydrogen bonds is modeled by positioning up to nine carbonic acid unit motifs in the cis-cis conformation so as to favor bifurcated H-bonding interactions. In this network, the two proton donor atoms belong to the same molecule as depicted in Fig. 1 for $n=9$.

\section{A. Energetics and cooperativity}

Table I shows the CP-corrected interaction energies, averaged over the number of bifurcated $\mathrm{H}$ bonds, of the fully optimized clusters up to $n=5$ computed using the 6-31 $+\mathrm{G}(d), 6-31+\mathrm{G}(d, p)$, and $6-311++\mathrm{G}(2 d, 2 p)$ basis sets. It is seen that all basis sets predict average interaction energies that are very close to one another. A similar result was noted in our previous work on linear chains of diformamide molecules, wherein both the 6-31+G(d) and 6-311+ $+\mathrm{G}(2 d, 2 p)$ basis sets (at the MP2 level) show an identical rise in H-bond energy upon going from diformamide dimer to pentamer. ${ }^{47}$ For computational convenience and given its relatively good performance, the interaction energies for the larger clusters were computed at the MP2/6-31+G(d) level.

Table II reports the MP2/6-31+G(d) BSSE-corrected dissociation energies before, $D_{e}$, and after, $D_{o}$, zero-point vibrational energy correction. It should be said that no scal-

TABLE I. MP2 interaction energies per bifurcated $\mathrm{H}$ bond, DE( $\mathrm{kcal} / \mathrm{mol})$, for cyclic clusters of carbonic acid, $\left(\mathrm{H}_{2} \mathrm{CO}_{3}\right)_{n}$.

\begin{tabular}{cccc}
\hline \hline$n$ & $6-31+\mathrm{G}(d)$ & $6-31+\mathrm{G}(d, p)$ & $6-311++\mathrm{G}(2 d, 2 p)$ \\
\hline 2 & -12.93 & -12.78 & -12.52 \\
3 & -14.55 & -14.41 & -14.92 \\
4 & -18.85 & -18.77 & -19.17 \\
5 & -20.63 & -20.60 & -20.84 \\
\hline \hline
\end{tabular}

TABLE II. Dissociation energies $(\mathrm{kcal} / \mathrm{mol})$ before, $D_{e}$, and after, $D_{o}$, zeropoint corrections; average dissociation energies, $\left\langle D_{e}\right\rangle$ and $\left\langle D_{o}\right\rangle$; and cooperativity factors in bifurcated $\mathrm{H}$-bonded cyclic clusters of $\left(\mathrm{H}_{2} \mathrm{CO}_{3}\right)_{n}$.

\begin{tabular}{rrrrrrrr}
\hline \hline & & & & & \multicolumn{2}{c}{ Cooperativity $^{\mathrm{a}}$} \\
\cline { 6 - 7 }$n$ & \multicolumn{1}{c}{$D_{e}$} & $\left\langle D_{e}\right\rangle^{\mathrm{b}}$ & \multicolumn{1}{c}{$D_{o}$} & $\left\langle D_{o}\right\rangle^{\mathrm{b}}$ & \multicolumn{1}{c}{$D_{e}$} & $D_{o}$ \\
\hline 2 & 12.93 & 12.93 & 11.52 & 11.52 & & \\
3 & 43.65 & 14.55 & 39.12 & 13.04 & 2.43 & 2.28 \\
4 & 75.40 & 18.85 & 67.76 & 16.94 & 7.89 & 7.23 \\
5 & 103.15 & 20.63 & 92.65 & 18.53 & 9.63 & 8.76 \\
6 & 129.18 & 21.53 & 116.52 & 19.42 & 10.32 & 9.48 \\
7 & 154.05 & 22.01 & 139.23 & 19.89 & 10.59 & 9.77 \\
8 & 178.48 & 22.31 & 161.52 & 20.19 & 10.72 & 9.91 \\
9 & 202.68 & 22.52 & 183.78 & 20.42 & 10.79 & 10.01 \\
\hline \hline
\end{tabular}

${ }^{a}$ Cooperativity factor defined as $\left[D_{n}-n D_{2}\right] /(n-1)$, where $D_{n}$ is the pertinent dissociation energy of the cluster of size $n$ and $D_{2}$ is that of the dimer. ${ }^{\mathrm{b}}\left\langle D_{e}\right\rangle$ and $\left\langle D_{o}\right\rangle$ are the dissociation energies divided by the number of bifurcated hydrogen bonds in a cluster of size $n$.

ing factor was used for the vibrational frequencies when determining the zero-point energy corrections. Also displayed are the corresponding average (per bifurcated $\mathrm{H}$ bond) dissociation energies $\left\langle D_{e}\right\rangle$, and $\left\langle D_{o}\right\rangle$. From Table II it can be shown that the dissociation energies increase in a fairly linear fashion with increasing size of the cluster. Formation of the first cyclic cluster, $n=3$, requires major bending distortions. For example, the $\mathrm{C}=\mathrm{O} \ldots \mathrm{C}$ and the $(\mathrm{C}=) \mathrm{O} \ldots \mathrm{C}=\mathrm{O}$ angles in the dimer are $159.9^{\circ}$ and $177.9^{\circ}$, respectively, compared with the corresponding values of $91.4^{\circ}$ and $148.6^{\circ}$ in the trimer. However, the three bifurcated $\mathrm{H}$ bonds in the cyclic trimer act cooperatively to offset the bending energy strain. In fact, the average dissociation energies (with and without vibrational corrections) for the trimer are about $13 \%$ higher than those in the dimer revealing the importance of cooperativity for overcoming the bending energy cost. Enlarging the ring size reduces the bending strain and produces a marked increase in the average dissociation energies. For example, the average dissociation energies for the tetramer are now about $46 \%$ higher than those found in the dimer. The percent increase, with respect to the dimer average dissociation energy $\left\langle D_{o}\right\rangle$, as a function of cluster size is conveniently presented in Fig. 2. The asymptotic percent increase for $\left\langle D_{o}\right\rangle$ is close to $80 \%$, which is larger than the extrapolated percent increase in the one-dimensional chains of three-center $\mathrm{H}$

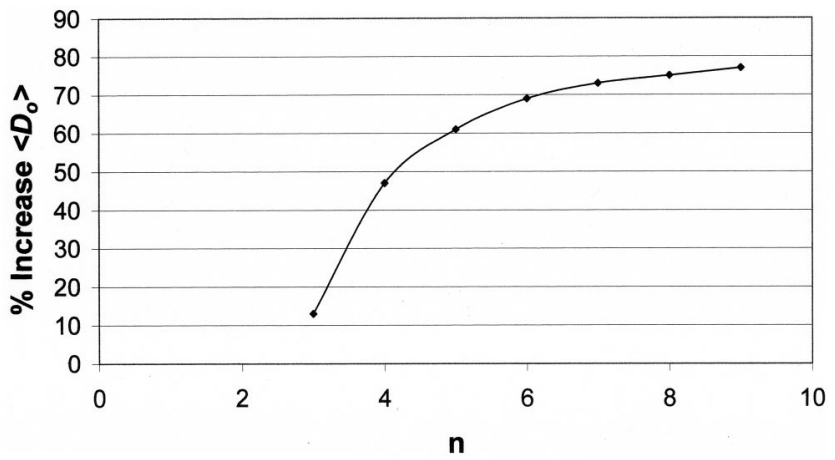

FIG. 2. Percent increase, relative to dimer, of the ZPVE-corrected dissociation energies averaged over the number of three-center $\mathrm{H}$ bonds, $\left\langle D_{o}\right\rangle$, as a function of the number of molecules in the ring, $n$. 
TABLE III. Relevant B3LYP/6-311+G(d) optimized bond lengths $R(\AA)$, angles A (degrees), and dihedrals $D($ degrees $)$ of $\left(\mathrm{H}_{2} \mathrm{CO}_{3}\right)_{n}$ clusters $(n=1-9)$. ${ }^{\mathrm{a}}$

\begin{tabular}{|c|c|c|c|c|c|c|c|c|c|c|}
\hline$n$ & $\mathrm{R}_{\mathrm{C}=\mathrm{O}}$ & $\mathrm{R}_{\mathrm{C}-\mathrm{O}}$ & $\mathrm{R}_{\mathrm{O}-\mathrm{H}}$ & $\mathrm{R}_{\mathrm{C}=\mathrm{O} \ldots \mathrm{H}}$ & $\mathrm{R}_{\mathrm{C}=\mathrm{O} \ldots \mathrm{C}}$ & $\mathrm{R}_{\mathrm{C} \ldots \mathrm{C}}$ & $\mathrm{R}_{\mathrm{H} \ldots \mathrm{H}}{ }^{\mathrm{e}}$ & $\mathrm{A}_{\mathrm{C}=\mathrm{O} \ldots \mathrm{C}}$ & $\mathrm{A}_{(\mathrm{C}=) \mathrm{O} \ldots \mathrm{C}=\mathrm{O}}$ & $\mathrm{D}_{\mathrm{C}-\mathrm{O}-\mathrm{H} \ldots \mathrm{H}}{ }^{\mathrm{e}}$ \\
\hline 1 & 1.186 & 1.362 & 0.966 & & & & 2.140 & & & 24.6 \\
\hline $2^{b}$ & 1.193 & 1.355 & 0.971 & & & & 2.018 & & & -0.4 \\
\hline $2^{c}$ & 1.201 & 1.342 & 0.967 & & & & 2.146 & & & 11.4 \\
\hline $2^{d}$ & 1.197 & 1.349 & 0.969 & 1.951 & 3.344 & 4.513 & 2.082 & 164.7 & 178.5 & 5.5 \\
\hline 3 & 1.218 & 1.331 & 0.977 & 1.995 & 3.116 & 3.372 & 2.077 & 91.4 & 148.7 & 8.3 \\
\hline 4 & 1.225 & 1.325 & 0.983 & 1.840 & 3.088 & 3.679 & 2.044 & 109.3 & 160.7 & 5.3 \\
\hline 5 & 1.227 & 1.322 & 0.985 & 1.792 & 3.079 & 3.859 & 2.030 & 121.6 & 166.9 & 3.6 \\
\hline 6 & 1.228 & 1.321 & 0.986 & 1.771 & 3.073 & 3.970 & 2.025 & 129.6 & 170.4 & 2.7 \\
\hline 7 & 1.228 & 1.320 & 0.986 & 1.762 & 3.072 & 4.047 & 2.024 & 136.1 & 172.5 & 2.2 \\
\hline 8 & 1.228 & 1.320 & 0.986 & 1.754 & 3.067 & 4.101 & 2.022 & 141.6 & 174.5 & 1.6 \\
\hline 9 & 1.228 & 1.319 & 0.987 & 1.751 & 3.065 & 4.130 & 2.024 & 144.8 & 175.1 & 1.4 \\
\hline
\end{tabular}

${ }^{\mathrm{a} I n t e r m o l e c u l a r ~ p a r a m e t e r s ~ s u c h ~ a s ~} \mathrm{R}_{\mathrm{C} \ldots \mathrm{C}}$ are measured between two adjacent molecules.

${ }^{\mathrm{b}}$ Geometry information for the proton donor unit.

${ }^{c}$ Geometry information for the proton acceptor unit.

${ }^{\mathrm{d}}$ Average geometry values for dimer.

${ }^{\mathrm{e}}$ Geometry parameters for the hydrogen atoms in the same molecule.

bonds of diformamide molecules $(62 \%),{ }^{47}$ and urea molecules $(55 \%) .{ }^{43}$ The ordering of cooperative enhancement in the calculated asymptotic $\left\langle D_{o}\right\rangle$ for carbonic acid $(20.70 \mathrm{kcal} / \mathrm{mol})$, diformamide $(14.18),{ }^{47}$ and urea $(10.70)^{43}$ supports the view that the degree of cooperativity is proportional to the strength of the $\mathrm{H}$ bond. ${ }^{35}$ The same conclusion is drawn if a graph of the percent increase of $\left\langle D_{e}\right\rangle$ vs $n$ is used instead.

The cooperativity factors listed also in Table II are suitably evaluated from the general formula ${ }^{11}$

$$
D_{\text {cooperativity }}=\left[D_{n}-n D_{2}\right] /(n-1), \quad n=3,4, \ldots,
$$

where $D$ represents the pertinent dissociation energies, $n$ is the number of units in the cluster, and $n-1$ stands for the additional bifurcated $\mathrm{H}$ bonds, relative to dimer, present in the cluster of size $n$. The trend in the cooperative factors correlates with that of the average dissociation energies. The relatively small values for $n=3$ reflects the energetic cost of bending as pointed out earlier. The cooperative factors grow by a factor of 4 upon enlarging the ring size from $n=3$, to $n=6$, after which they begin to converge toward their limiting values.

\section{B. Equilibrium geometries}

Table III shows relevant structural parameters for the B3LYP/ 6-311+ $\mathrm{G}(d)$ optimized clusters including the monomer. The monomer parameters are close to those reported in previous studies at the MP2/6-31G $(d)$ level. ${ }^{69}$ The repulsive interaction between the hydrogen atoms is minimized by a dihedral angle $D_{\mathrm{C}-\mathrm{O}-\mathrm{H} \ldots \mathrm{H}}$ of $25^{\circ}$. The minimum energy structure for the dimer turns out to be nonplanar as indicated by the $\mathrm{A}_{\mathrm{C}=\mathrm{O} \ldots \mathrm{C}}$ angle of $165^{\circ}$, where $\mathrm{C}=\mathrm{O}$ is that of the proton acceptor unit. In fact, the planar linear dimer turns out to be a saddle point of second order. Upon dimer formation, the two hydrogens of the proton donor unit are now in the same plane, whereas those in the proton acceptor unit remain in different planes, although the $\mathrm{D}_{\mathrm{C}-\mathrm{O}-\mathrm{H} . . \mathrm{H}}$ is substantially lowered relative to the monomer. The bifurcated hydrogen bond in the dimer causes an elongation of the $R_{\mathrm{C}=\mathrm{O}}$ bond, and a contraction of the $R_{\mathrm{C}-\mathrm{O}}$ bonds in both the donor and acceptor units. The $\mathrm{R}_{\mathrm{O}-\mathrm{H}}$ bonds in the proton-donor unit are lengthened, while they remain fairly unchanged in the acceptor unit. Geometry optimization of the linear trimer resulted in two imaginary frequencies. By perturbing the geometry in the direction of the imaginary frequencies, the symmetric $\left(C_{3 h}\right.$ point group) cyclic cluster resulted as the minimum energy structure. Likewise, the larger clusters belong to a corresponding $C_{n h}$ point group. It should be noted that no symmetry constraints were introduced in the optimization of the clusters. The formation of the ring-like structure in the trimer brings about notorious changes in the structural parameters relative to the dimer geometry. One striking geometrical change is the required bending of the units to adopt the cyclic structure. The $\mathrm{A}_{\mathrm{C}=\mathrm{O} \ldots \mathrm{C}}$ angle is reduced from $165^{\circ}$ in the dimer to $91^{\circ}$ in the trimer. Further indication of

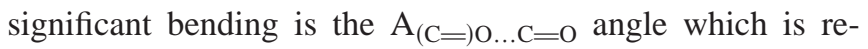
duced from $178^{\circ}$ to $149^{\circ}$. The geometry distortions give rise to a longer $\mathrm{H}$-bond distance $R_{\mathrm{C}=\mathrm{O} \ldots \mathrm{H}}$ in the trimer compared to that in the dimer. With such considerable distortions, we would expect the average dissociation energy for $n=3$ to be much lower than that for $n=2$. However, cooperative effects in the trimer more than compensate for the energy cost of structural bending, and lead to a cyclic structure with en-

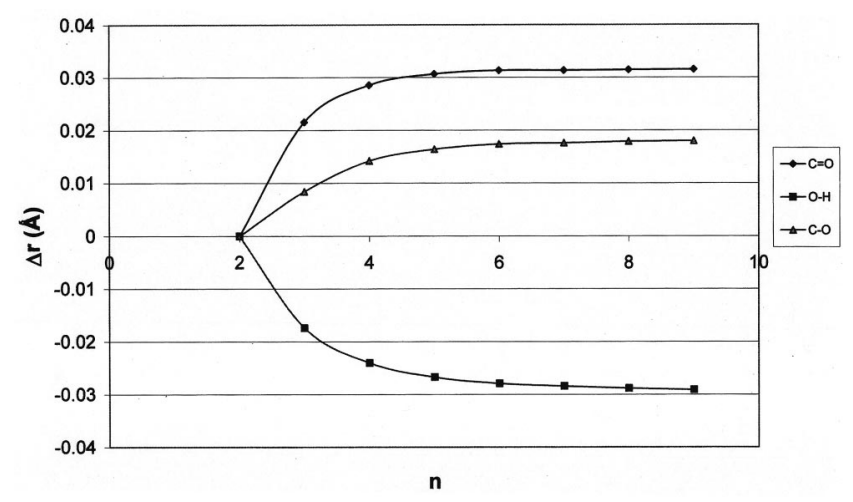

FIG. 3. Changes with respect to dimer geometry of relevant intramolecular bond lengths, $\Delta r(\AA)$, as a function of the number of molecules in the ring, $n$. 


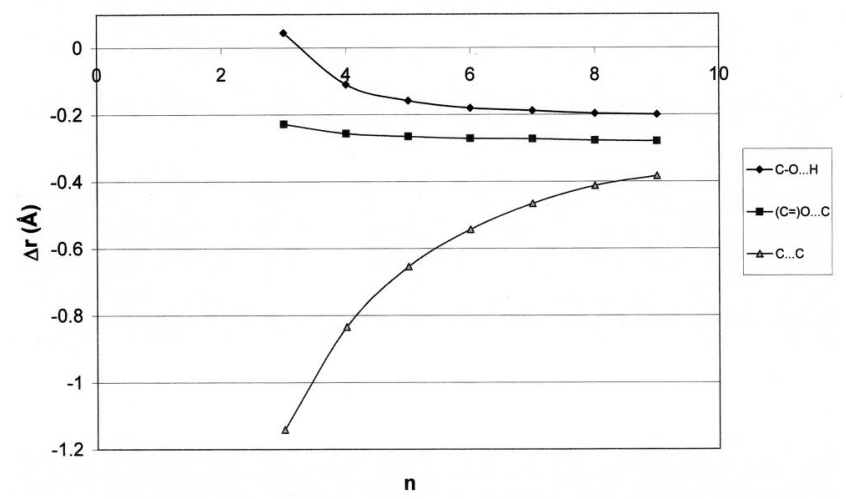

FIG. 4. Changes with respect to dimer geometry of relevant intermolecular bond lengths, $\Delta r(\AA)$, as a function of the number of molecules in the ring, $n$.

hanced stability. For the larger clusters, the cooperative effects are more pronounced in the structural parameters. Trends in the $R_{\mathrm{C}=\mathrm{O}}$, and $\mathrm{R}_{\mathrm{O}-\mathrm{H}}$ elongation, and the $R_{\mathrm{C}-\mathrm{O}}$ contractions can be conveniently appreciated by plotting the shifts of the bond distances, relative to the corresponding average values in the dimer, versus the size of the cluster $n$. Figure 3 shows that the cooperative enhancement as reflected in these geometrical parameters attains saturation when $n$ =7. A similar result is found by following the evolution of the intermolecular parameters $R_{\mathrm{C}=\mathrm{O} \ldots \mathrm{H}}, R_{(\mathrm{C}=) \mathrm{O} \ldots \mathrm{C}}$, and $R_{\mathrm{C} \ldots \mathrm{C}}$ displayed in Fig. 4 . Thus, the evolution of relevant intra- and intermolecular parameters attests to the energetic evolution shown in Table II and Fig. 2.

\section{Infrared stretching frequencies and vibrational intensities}

Table IV shows the $\mathrm{B} 3 \mathrm{LYP} / 6-311+\mathrm{G}(d)$ symmetric $\nu_{\mathrm{O}-\mathrm{H}}$ stretching frequencies, and the $\nu_{\mathrm{C}=\mathrm{O}}$ stretching frequencies along with their corresponding intensities. The symmetric $\nu_{\mathrm{O}-\mathrm{H}}$ stretching frequencies were conveniently chosen because of their high intensities compared with the asymmetric ones. It should be mentioned however, that for clusters with $n \geqslant 3$ and because of symmetry, there is more than just one $\nu_{\mathrm{O}-\mathrm{H}}$ stretching frequency. In fact, a given $\nu_{\mathrm{O}-\mathrm{H}}$ stretching frequency is associated with a collective motion of the $\mathrm{O}-\mathrm{H}$ bonds in the different units. In all clusters, the asymmetric $\mathrm{O}-\mathrm{H}$ stretching modes have very low to zero intensity (symmetry forbidden). The collective symmetric $\mathrm{O}-\mathrm{H}$ stretching modes are found with both very high and close to zero intensity, depending on the overall symmetry of a given stretching mode. As mentioned earlier, we focus on the symmetric $\mathrm{O}-\mathrm{H}$ modes with high intensities for the discussion of cooperativity.

Dimer formation is accompanied by a sizable redshift of the $\mathrm{O}-\mathrm{H}$ stretching mode in the proton donor unit $\left(\Delta \nu_{\mathrm{O}-\mathrm{H}}\right.$ $=-66 \mathrm{~cm}^{-1}$ ) with no significant change in the proton acceptor unit. Also, the $\mathrm{C}=\mathrm{O}$ stretching mode is shifted to the red in both the donor $\left(\Delta \nu_{\mathrm{C}=\mathrm{O}}=-15 \mathrm{~cm}^{-1}\right)$ and acceptor $\left(\Delta \nu_{\mathrm{C}=\mathrm{O}}=-59 \mathrm{~cm}^{-1}\right)$ units, with the shift being larger in the latter. These redshifts increase with increasing size of the clusters, an explicit manifestation of cooperativity. In particular, the trends of the $\nu_{\mathrm{O}-\mathrm{H}}$, and $\nu_{\mathrm{C}=\mathrm{O}}$ frequency shifts in the cyclic clusters relative to that in the smallest cyclic cluster, $n=3$, are represented in Fig. 5 as functions of $1 / n$. It is seen that the $\nu_{\mathrm{C}=\mathrm{O}}$ frequency shifts can be fit by a linear equation, whereas the $\nu_{\mathrm{O}-\mathrm{H}}$ frequency shifts follow a quadratic correlation. Using these correlations, we find that the estimated shifts, relative to trimer, in the limit of $n=\infty$ are -117 and $-214 \mathrm{~cm}^{-1}$ for $\Delta \nu_{\mathrm{C}=\mathrm{O}}$ and $\Delta \nu_{\mathrm{O}-\mathrm{H}}$, respectively, with the negative signs indicating shifts to the red. The limiting value of $\Delta \nu_{\mathrm{O}-\mathrm{H}}$ is particularly close to that in the nonamer $\left(\Delta \nu_{\mathrm{O}-\mathrm{H}}=209 \mathrm{~cm}^{-1}\right)$. Obtaining reliable frequency shifts in the limit of $n=\infty$ is important because of the relationship between frequency shifts and average (per bifurcated $\mathrm{H}$ bond), dissociation energies. Figure 6 is a graph of the average dissociation energies $\left\langle D_{e}\right\rangle$, and $\left\langle D_{o}\right\rangle$, as functions of the $\nu_{\mathrm{O}-\mathrm{H}}$ frequency shifts relative to trimer. Using the linear fits for these functions and the limiting value for $\Delta \nu_{\mathrm{O}-\mathrm{H}}$, the dissociation energies $\left\langle D_{e}\right\rangle$, and $\left\langle D_{o}\right\rangle$ are estimated to converge to 22.8 and to $20.6 \mathrm{kcal} / \mathrm{mol}$, respectively in the limit

TABLE IV. Relevant stretching frequencies $\left(\mathrm{cm}^{-1}\right)$, intensities $A(\mathrm{kcal} / \mathrm{mol})$, intensity ratios, and cooperativity factors $\left(\mathrm{cm}^{-1}\right)$ in $\left(\mathrm{H}_{2} \mathrm{CO}_{3}\right)_{n}$ clusters.

\begin{tabular}{|c|c|c|c|c|c|c|c|c|}
\hline \multirow[b]{2}{*}{$n$} & \multirow[b]{2}{*}{$\nu_{\mathrm{OH}}{ }^{\mathrm{a}}$} & \multirow[b]{2}{*}{$\nu_{\mathrm{CO}}$} & \multirow[b]{2}{*}{$\mathrm{A}_{\mathrm{OH}}$} & \multirow[b]{2}{*}{$\mathrm{A}_{\mathrm{C}=\mathrm{O}}$} & \multirow[b]{2}{*}{$\left(\mathrm{A}_{\mathrm{OH}}\right)_{n} /\left(\mathrm{A}_{\mathrm{OH}}\right)_{1}$} & \multirow[b]{2}{*}{$\left(\mathrm{A}_{\mathrm{C}=\mathrm{O}}\right)_{n} /\left(\mathrm{A}_{\mathrm{C}=\mathrm{O}}\right)_{1}$} & \multicolumn{2}{|c|}{ Cooperativity $^{\mathrm{c}}$} \\
\hline & & & & & & & $\mathrm{A}_{\mathrm{OH}}$ & $\mathrm{A}_{\mathrm{C}=\mathrm{O}}$ \\
\hline 1 & 3773 & 1908 & 51 & 468 & 1 & 1 & & \\
\hline \multirow[t]{2}{*}{$2^{\mathrm{b}}$} & 3707 & 1893 & 675 & 215 & 13 & 0.5 & & \\
\hline & 3777 & 1849 & 84 & 1212 & 2 & 3 & & \\
\hline 3 & 3609 & 1812 & 706 & 657 & 14 & 1 & 0 & 0 \\
\hline 4 & 3502 & 1784 & 1908 & 1187 & 37 & 3 & 60 & 19 \\
\hline 5 & 3454 & 1767 & 3238 & 1882 & 63 & 4 & 82 & 31 \\
\hline 6 & 3428 & 1754 & 4626 & 2690 & 91 & 6 & 89 & 38 \\
\hline 7 & 3417 & 1750 & 5935 & 3563 & 116 & 8 & 88 & 41 \\
\hline 8 & 3408 & 1738 & 7373 & 4449 & 145 & 10 & 86 & 42 \\
\hline 9 & 3401 & 1732 & 8767 & 5379 & 172 & 11 & 82 & 42 \\
\hline
\end{tabular}

${ }^{\mathrm{a}}$ Symmetric stretching frequencies.

${ }^{\mathrm{b}}$ The first row for $n=2$ corresponds to the proton donor, and the second row to the proton acceptor.

${ }^{\mathrm{c}}$ Cooperativity factors defined relative to the smallest cyclic cluster as $\left[A_{n} / n-A_{3} / 3\right] / n$, where $A$ is the pertinent intensity of the cluster of size $n$ and $A_{3}$ is that of the trimer. 


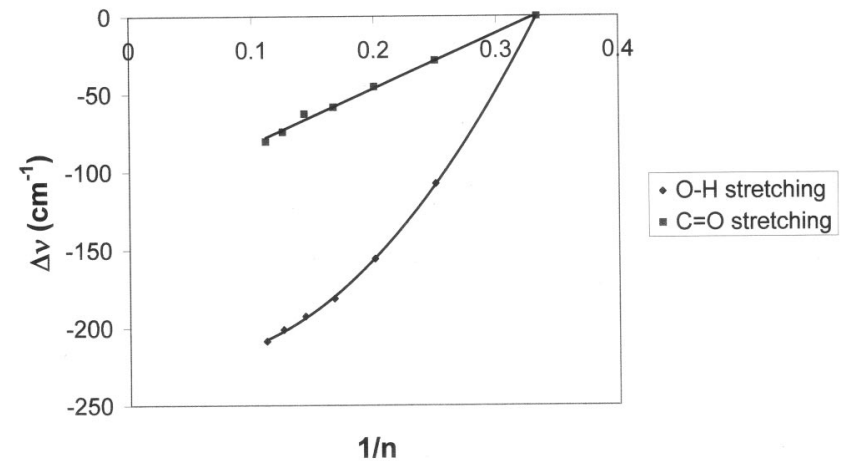

FIG. 5. Changes, relative to dimer, of the B3LYP/6-311+G(d) harmonic stretching frequencies $\left(\mathrm{cm}^{-1}\right), \nu_{\mathrm{C}=\mathrm{O}}$ and $\nu_{\mathrm{O}-\mathrm{H}}$, as a function of $1 / n$, with $n=$ number of molecules in the ring.

of $n=\infty$. These limiting values represent a percent increase of over $77 \%$. A very similar result for $\left\langle D_{o}\right\rangle$ was noted already by inspection of Fig. 2.

Another useful indicator of hydrogen bonding is the magnification of the vibrational intensities, $\mathrm{A}_{\mathrm{O}-\mathrm{H}}$, and $\mathrm{A}_{\mathrm{C}=\mathrm{O}}$. Thus, the $\nu_{\mathrm{O}-\mathrm{H}}$ intensity (donor unit) in the dimer is about 13 times more intense than that in the monomer. The corresponding $\nu_{\mathrm{C}=\mathrm{O}}$ (acceptor unit) intensity in the dimer is almost three times that of the monomer. For the cyclic clusters, $n \geqslant 3$, the intensification ratios grow linearly with increasing size of the cluster. The convergence of the intensification for $\nu_{\mathrm{C}=\mathrm{O}}$ and $\nu_{\mathrm{O}-\mathrm{H}}$ stretching modes in the cyclic clusters can be gleaned from the last two columns of Table IV. Here, the cooperativity factors are conveniently defined in terms of the smallest cyclic cluster, trimer as

$$
A_{\text {cooperativity }}=\left[A_{n} / n-A_{3} / 3\right] / n, \quad n=3,4, \ldots,
$$

where $A$ represents the pertinent intensities $\nu_{\mathrm{C}=\mathrm{O}}$ or $\nu_{\mathrm{O}-\mathrm{H}}$ for a cluster of size $n$. Figure 7 shows a convenient display of the results. It is apparent again that cooperativity as reflected in these parameters is already close to saturation for $n=9 .^{70}$

\section{NBO ANALYSIS}

Earlier reports ${ }^{35,47,71,72}$ have shown the importance of the role of charge transfer interactions involved in the H-bond formations. Molecular units acting simultaneously as both $\mathrm{H}$-bond donor and $\mathrm{H}$-bond acceptor form extended chains or

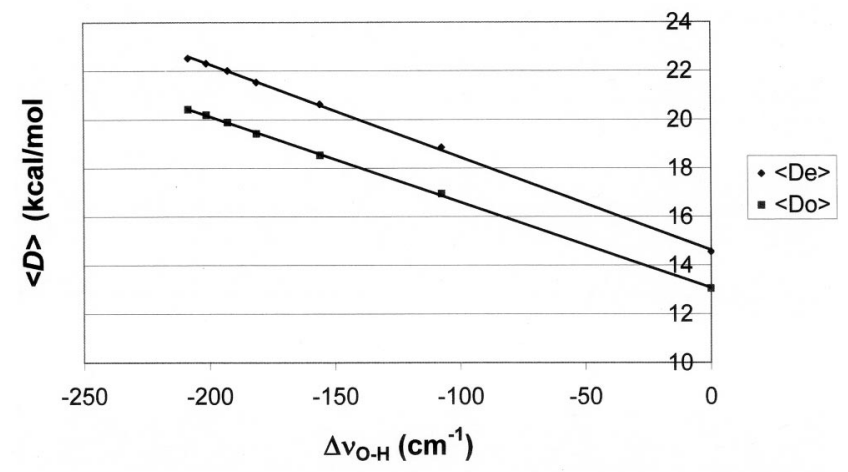

FIG. 6. Average dissociation energies $(\mathrm{kcal} / \mathrm{mol})$ of the cyclic clusters as a function of the corresponding $\mathrm{O}-\mathrm{H}$ stretching frequencies $\left(\mathrm{cm}^{-1}\right)$, shifted to the red relative to the smallest cyclic cluster $n=3$.

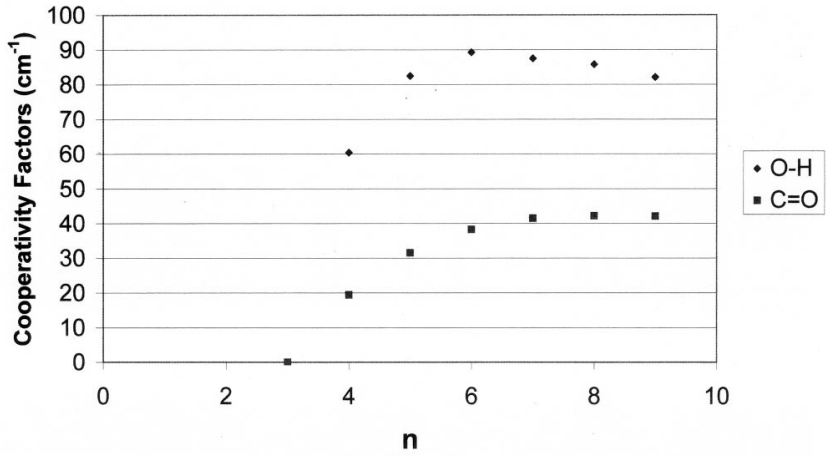

FIG. 7. Cooperativity factors $\left(\mathrm{cm}^{-1}\right)$ of the cyclic clusters, relative to trimer, based on the intensities of the stretching frequencies, $\nu_{\mathrm{C}=\mathrm{O}}$ and $\nu_{\mathrm{O}-\mathrm{H}}$.

rings in which individual hydrogen bond enhances the strength of each other by mutual polarization. We employed the NBO method and the HF/6-311++G $(d, p)$ level for analyzing wave functions of the B3LYP/6-311+ $\mathrm{G}(d)$ optimized ring-like carbonic acid clusters. The charge transfer from the acceptor oxygen lone pairs to the antibonding $\mathrm{O}-\mathrm{H}$ orbitals, $\left(n_{\mathrm{O}} \rightarrow \sigma_{\mathrm{O}-\mathrm{H}}^{*}\right)$, is calculated and examined along with the associated delocalization energies.

\section{A. Delocalization energies}

An examination of all possible interactions between "filled" (electron-donor) Lewis-type NBOs and "empty" (electron-acceptor) non-Lewis NBOs, allows us to estimate their energetic importance by second-order perturbation theory. In the carbonic acid cyclic clusters studied here, the transfer of electron density from the lone pairs of the acceptor oxygen atom, $n_{\mathrm{O}}$, to the antibonding orbitals of the $\mathrm{O}-\mathrm{H}$ bonds in the proton donor, $\sigma_{\mathrm{O}-\mathrm{H}}^{*}$, is seen to give the strongest stabilization energy. The delocalization energies due to $n_{\mathrm{O}}$ $\rightarrow \sigma_{\mathrm{O}-\mathrm{H}}^{*}$ charge transfers can be approximated by ${ }^{70}$

$$
E_{n \rightarrow \sigma^{*}}^{(2)} \approx(-2) F\left(n, \sigma^{*}\right)^{2} /\left(\bar{C}_{\sigma^{*}-\bar{C}_{n}}\right),
$$

where $\bar{C}_{\sigma^{*}}$, and $\bar{C}_{n}$ are diagonal elements (orbital energies), and $F\left(n, \sigma^{*}\right)$ is the corresponding off-diagonal NBO Fock matrix element. The average results, per bifurcated hydrogen bond, are presented in Table $\mathrm{V}$ for the cyclic clusters. These stabilization energies are considered to be important contributions to the cooperative enhancement of the H-bonding

TABLE V. Average NBO delocalization energies $\left\langle E^{2}\right\rangle(\mathrm{kcal} / \mathrm{mol})$, and charge transfer $n_{\mathrm{o}} \rightarrow \sigma_{\mathrm{O}-\mathrm{H}}^{*},\langle q\rangle($ a.u. $){ }^{\mathrm{a}}$

\begin{tabular}{ccc}
\hline \hline$n$ & $\left\langle E^{2}\right\rangle$ & $\langle q\rangle$ \\
\hline 3 & 7.90 & 0.002320 \\
4 & 19.18 & 0.005592 \\
5 & 25.60 & 0.007479 \\
6 & 29.42 & 0.008572 \\
7 & 31.52 & 0.009244 \\
8 & 33.40 & 0.009740 \\
9 & 34.28 & 0.009971
\end{tabular}

$\overline{\mathrm{a}} \mathrm{HF} / 6-311++\mathrm{G}(d, p) \mathrm{NBO}$ values averaged over the number of bifurcated $\mathrm{H}$ bonds, and calculated using the B3LYP/6-311+ $\mathrm{G}(d)$ optimized geometries. 


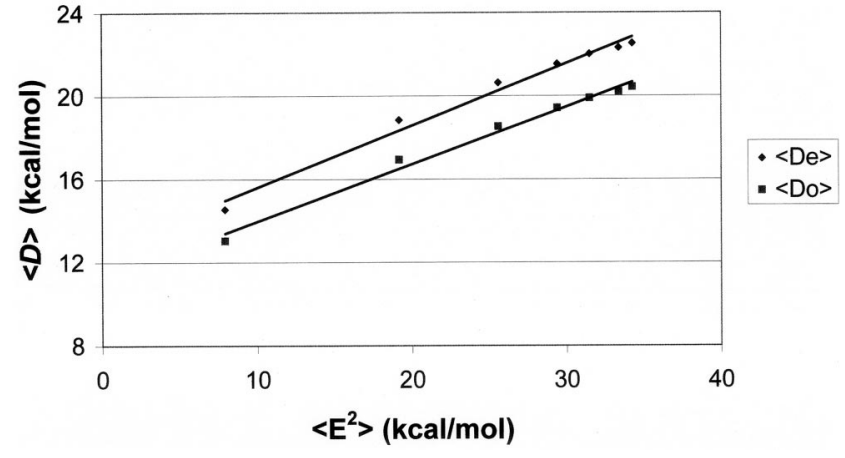

FIG. 8. Average dissociation energies $(\mathrm{kcal} / \mathrm{mol})$ of the cyclic clusters as a function of the average NBO delocalization energies $\left\langle E^{2}\right\rangle(\mathrm{kcal} / \mathrm{mol})$.

interactions. It is seen that the average $\left\langle E^{(2)}\right\rangle$ in the tetramer is more than twice that in the trimer. The cooperativity increases further in the larger clusters approaching an asymptotic value of about $35 \mathrm{kcal} / \mathrm{mol}$ as $n \rightarrow \infty$. It is convenient to examine the relationship between the average second-order stabilization energies, $\left\langle E^{(2)}\right\rangle$, and the average dissociation energies, $\left\langle D_{e}\right\rangle$ or $\left\langle D_{o}\right\rangle$. A graphical representation of these parameters is displayed in Fig. 8, where it is evident that the average second-order stabilization energies for the clusters of size $n=3$ to $n=9$ correlate linearly with the corresponding dissociation energies. Using an estimated limiting value of $35 \mathrm{kcal} / \mathrm{mol}$ for $\left\langle E^{(2)}\right\rangle$, and the linear fitting equations of Fig. 8, we obtain converged values for $\left\langle D_{e}\right\rangle$ and $\left\langle D_{o}\right\rangle$ of 23.0 and $20.8 \mathrm{kcal} / \mathrm{mol}$, respectively. These values compare remarkably well with the previously estimated values obtained using the relationship between $\Delta \nu_{\mathrm{O}-\mathrm{H}}$ shifts and average dissociation energies.

\section{B. Charge distributions}

The NBO analysis of the wave functions provides information about charge distribution over the clusters. The average amount, per bifurcated hydrogen bond, of $n_{\mathrm{O}} \rightarrow \sigma_{\mathrm{O}-\mathrm{H}}^{*}$ charge transferred in a given cluster can be estimated by ${ }^{90}$

$$
q_{n \rightarrow \sigma^{*}} \approx 2\left\{F\left(n, \sigma^{*}\right) /\left(\bar{C}_{\sigma^{*}}-\bar{C}_{n}\right)\right\}^{2},
$$

where the meaning of $F\left(n, \sigma^{*}\right), \bar{C}_{\sigma^{*}}$, and $\bar{C}_{n}$ were given earlier. The results for the cyclic clusters are exhibited in Table V. The cyclic clusters of carbonic acid display important cooperativity, with a marked rising of the amount of charge transfer as the ring size grows. Thus, the electron density flow from the proton donor unit to the proton acceptor unit causes a mutual polarization which results in the enhancement of the proton donor and acceptor capabilities of the respective units. The enhanced donor and acceptor capabilities result in a cooperative strengthening of each individual bifurcated hydrogen bond. As with the other indicators used in this work, the cooperative effects manifested in the $n_{\mathrm{O}}$ $\rightarrow \sigma_{\mathrm{O}-\mathrm{H}}^{*}$ charge transfer are close to convergence in the largest cluster.

\section{CONCLUSION}

We have shown that cooperative effects play a significant role in the stabilization of ring-like networks containing bifurcated $\mathrm{H}$-bonding interaction of the $\mathrm{H}_{1} \ldots \mathrm{A}$... $\mathrm{H}_{2}$ type where the two proton-donors are in the same molecule. Carbonic acid in its cis-cis form was used as the basic structural motif to construct the two-dimensional network consisting of ring-like structures of up to nine monomers. Although the cis-cis geometry configuration is the least stable of the three minimum-energy isomers of carbonic acid, it benefits considerably from the cooperativity effects present in ring-like networks of three-centered H-bonding interactions. Therefore, ring-like clusters rather than the monomer or dimer offer an important alternative for investigating the stability of cis-cis carbonic acid. A similar conclusion has been made for the trans-trans carbonic acid monomer in regard to its dimer, and linear $\mathrm{H}$-bonded analogs of the trans-trans dimer. ${ }^{42,53}$ Interestingly, while two conventional two-centered $\mathrm{H}$ bonds stabilize the trans-trans dimer, a three-centered $\mathrm{H}$ bond is responsible for stabilizing the cis-cis dimer of carbonic acid. Thus, although three-centered H-bond interactions can be viewed as a consequence of proton deficiency, in some cases they may also be considered as the natural result of an interaction that is itself energetically favorable and capable of defining the complex behavior of certain molecules into their oligomeric clusters In this study, the cooperative effects were manifested in the energetics, geometry, $\mathrm{O}-\mathrm{H}$ and $\mathrm{C}=\mathrm{O}$ stretching frequencies and intensities. The cooperative effects were also rationalized using the NBO method. It is shown that the cooperative effects nearly saturate for the largest cluster considered, $n=9$. The estimated average dissociation energy, corrected for zero-point vibrational energy, as $n=\rightarrow \infty$ is $20.6 \mathrm{kcal} / \mathrm{mol}$, which represents a $79 \%$ cooperative enhancement relative to the corresponding value in the dimer. Though there is still a lack of experimental evidence necessary to support our study, our results may stimulate further experimental and theoretical investigations of systems containing bifurcated hydrogen bonding. We are currently interested in molecules or polymers consisting of comparable bifurcated hydrogen bonds especially in parallel and antiparallel $\beta$ sheets of proteins for which the mean geometries have been previously determined by Fabiola et al. ${ }^{72}$

\section{ACKNOWLEDGMENTS}

This research was supported by a start-up funding and a Faculty Research and Development grant at DePaul University (RDP), and also by grants from NSF, DOE's Office of Basic Energy Sciences (Materials Science and Engineering Division), and Nebraska Research Initiatives (X.C.Z.) and by the Research Computing Facility and Bioinformatics Facility at the University of Nebraska-Lincoln.

${ }^{1}$ R. Parthasarathy, Acta Crystallogr., Sect. B: Struct. Crystallogr. Cryst. Chem. 25, 509 (1969)

${ }^{2}$ P. G. Johnson and A. Kvick, Acta Crystallogr., Sect. B: Struct. Crystallogr. Cryst. Chem. 28, 1827 (1972).

${ }^{3}$ G. A. Jeffrey and S. Takagi, Acc. Chem. Res. 11, 264 (1978).

${ }^{4}$ C. H. Gorbitz and M. C. Etter, J. Chem. Soc., Perkin Trans. 2 1992, 131.

${ }^{5}$ C. Huang, L. A. Cabell, and E. A. Anslyn, J. Am. Chem. Soc. 116, 2278 (1994).

${ }^{6}$ H. C. M. Nelson, J. T. Finch, B. F. Luisi, and A. Klug, Nature (London) 330, 221 (1987).

${ }^{7}$ J. E. Koehler, W. Saenger, and W. F. van Gunsteren, J. Biomol. Struct. Dyn. 6, 181 (1988). 
${ }^{8}$ R. Preissner, U. Egner, and W. Saenger, FEBS Lett. 288, 192 (1991).

${ }^{9}$ D. S. Goodwell, M. L. Kopka, and R. E. Dickerson, Biochemistry 34 4983 (1995).

${ }^{10}$ A. Karpfen, Adv. Chem. Phys. 123, 469 (2002), and references therein.

${ }^{11}$ S. Scheiner, Hydrogen Bonding: A Theoretical Perspective (Oxford University Press, New York, 1997), Chap. 5 and references therein.

${ }^{12}$ G. R. Desiraju and T. Steiner, The Weak Hydrogen Bond (Oxford University Press, New York, 1997), pp 80-86.

${ }^{13}$ G. A. Jeffrey, An Introduction to Hydrogen Bonding (Oxford University Press, New York, 1997), Chap. 6.

${ }^{14}$ H. Kleeberg, D. Klein, and W. A. P. Luck, J. Phys. Chem. 91, 3200 (1987).

${ }^{15}$ E. Clementi, W. Kolos, G. C. Lie, and W. Ranghino, Int. J. Quantum Chem. 17, 377 (1980).

${ }^{16}$ P. L. Huyskens, J. Am. Chem. Soc. 99, 2578 (1977).

${ }^{17}$ P. Kollman, J. Am. Chem. Soc. 99, 4875 (1977).

${ }^{18}$ J. E. Del Bene and J. A. Pople, Chem. Phys. Lett. 4, 426 (1969).

${ }^{19}$ H. S. Frank and W. Y. Wen, Discuss. Faraday Soc. 24, 133 (1957).

${ }^{20}$ A. K. Sum and S. I. Sandler, J. Phys. Chem. 104, 1121 (2000).

${ }^{21}$ R. D. Parra and X. C. Zeng, J. Chem. Phys. 110, 6329 (1999).

${ }^{22}$ W. E. Doering, R. D. Parra, and X. C. Zeng, J. Mol. Struct.: THEOCHEM 431, 119 (1998).

${ }^{23}$ F. C. Hagemeister, C. J. Gruenloh, and T. S. Zwier, J. Phys. Chem. A 102, 82 (1998)

${ }^{24}$ O. Mó, M. Yáñez, and J. Elguero, J. Chem. Phys. 107, 3592 (1997).

${ }^{25}$ A. Karpfen, in Molecular Interactions, edited by S. Scheiner (Wiley, New York, 1997), Chap. 8.

${ }^{26}$ B. F. King and F. Weinhold, J. Chem. Phys. 103, 3333 (1995).

${ }^{27}$ S. Suhai, J. Chem. Phys. 101, 9766 (1994).

${ }^{28}$ R. Ludwig, O. Reis, R. Winter, F. Weinhold, and T. C. Farrar, J. Phys. Chem. B 102, 9312 (1998).

${ }^{29}$ H. Guo, N. Gresh, B. P. Roques, and D. R. Salahub, J. Phys. Chem. B 104, 9746 (2000).

${ }^{30}$ K. Nadya, P. Lillyrose, Emma del Rio, and J. J. Dannenberg, J. Am. Chem. Soc. 123, 4348 (2001).

${ }^{31}$ C. Guo, M. S. Cheung, H. Levine, and D. A. Kessler, J. Chem. Phys. 116, 4353 (2002).

${ }^{32}$ D. B. Dupré and M. C. Yappert, J. Phys. Chem. A 106, 567 (2002).

${ }^{33}$ I. Vorobyov, M. C. Yappert, and D. B. Dupré, J. Phys. Chem. A 106, 10691 (2002)

${ }^{34}$ N. Kobbo and J. J. Dannenberg, J. Phys. Chem. A 107, 6688 (2003).

${ }^{35}$ T. Kar and S. Scheiner, J. Phys. Chem. A 108, 9161 (2004).

${ }^{36}$ I. Rozas, I. Alkorta, and J. Elguero, J. Phys. Chem. A 102, 9925 (1998).

${ }^{37}$ R. D. Parra, M. Furukawa, B. Gong, and X. C. Zeng, J. Chem. Phys. 115, 6030 (2001).

${ }^{38}$ J. H. Yang and S. H. Gellman, J. Am. Chem. Soc. 120, 9090 (1998).

${ }^{39}$ J. H. Yang, L. A. Christianson, and S. H. Gellman, Org. Lett. 1, 11 (1999).

${ }^{40}$ R. D. Parra, B. Gong, and X. C. Zeng, J. Chem. Phys. 115, 6036 (2001).
${ }^{41}$ A. Rybarczyk-Pirek, S. J. Grabowski, and J. Nawrot-Modranka, J. Phys. Chem. A 107, 9233 (2003).

${ }^{42}$ R. F. Bader, Atoms in Molecules: A Quantum Theory (Oxford University Press, New York, 1990).

${ }^{43}$ A. Masunov and J. J. Dannenberg, J. Phys. Chem. B 104, 806 (2000).

${ }^{44}$ S. Dong, R. Ida, and G. Wu, J. Phys. Chem. A 104, 1194 (2000).

${ }^{45}$ T. Lan and L. W. McLaughin, J. Am. Chem. Soc. 123, 2064 (2001), and references therein.

${ }^{46}$ M. Meyer, M. Brandl, and J. Sühnel, J. Phys. Chem. A 105, 8223 (2001).

${ }^{47}$ R. D. Parra, S. Bulusu, and X. C. Zeng, J. Chem. Phys. 118, 3499 (2003).

${ }^{48}$ C. A. Wight and A. I. Boldyrev, J. Phys. Chem. 9912125 (1995).

${ }^{49}$ R. Janoschek and I. G. Csizmadia, J. Mol. Struct. 300, 637 (1997).

${ }^{50}$ B. Montanari, P. Ballone, and R. O. Jones, Macromolecules 32, 3396 (1999).

${ }^{51}$ M. T. Nguyen and T. K. Ha, J. Am. Chem. Soc. 106, 599 (1984).

${ }^{52}$ K. R. Liedl, S. Sekusak, and E. Mayer, J. Am. Chem. Soc. 119, 3782 (1997).

${ }^{53}$ P. Ballone, B. Montanari, and R. O. Jones, J. Chem. Phys. 112, 6571 (2000).

${ }^{54}$ W. Hage, K. R. Liedl, A. Hallbrucker, and E. Mayer, Science 279, 1332 (1998).

${ }^{55}$ M. T. Nguyen, G. Raspoet, and L. G. Vanquickenborne, J. Phys. Chem. A 101, 7379 (1997).

${ }^{56}$ M. J. Frisch, G. W. Trucks, H. B. Schlegel et al., Gaussian, Inc., Wallingford CT (2004). M. J. Frish, G. W. Trucks, H. B. Schlegel et al., GAUSSIAN 03, Revision C.02, Gaussian, Inc., Wallingford, CT (2004).

${ }^{57}$ A. D. Becke, J. Chem. Phys. 98, 5648 (1993).

${ }^{58}$ C. Lee, W. Yang, and R. G. Parr, Phys. Rev. B 37, 785 (1988).

${ }^{59}$ S. Suhai, J. Phys. Chem. 99, 1172 (1995).

${ }^{60}$ J. E. Del Bene, W. B. Person, and K. Szczepaniak, J. Phys. Chem. 99, 10705 (1995).

${ }^{61}$ J. J. Novoa and C. Sosa, J. Phys. Chem. 99, 15873 (1995).

${ }^{62}$ L. Gonzalez, O. Mo, M. Yanez, and J. Elguero, J. Mol. Struct.: THEOCHEM 371, 1 (1996).

${ }^{63}$ O. Mo, M. Yanez, and J. Elguero, J. Chem. Phys. 107, 3592 (1997).

${ }^{64}$ F. C. Hagemeister, C. J. Gruenloh, and T. S. Zwier, J. Phys. Chem. 102, 82 (1998).

${ }^{65}$ S. S. Xantheas, J. Chem. Phys. 102, 4505 (1995).

${ }^{66}$ S. F. Boys and F. Bernardi, Mol. Phys. 19, 553 (1970).

${ }^{67}$ S. Simon, M. Duran, and J. J. Dannenberg, J. Phys. Chem. 103, 1640 (1999).

${ }^{68}$ S. Simon, M. Duran, and J. J. Dannenberg, J. Chem. Phys. 105, 11024 (1996).

${ }^{69}$ C. A. Wight and A. I. Boldyrev, J. Phys. Chem. 9912125 (1995).

${ }^{70}$ A. E. Reed, L. A. Curtiss, and F. Weinhold, Chem. Rev. (Washington, D.C.), 88, 899 (1988), and references therein.

${ }^{71}$ B. F. King and F. Weinhold, J. Chem. Phys. 103, 3333 (1995).

${ }^{72}$ G. F. Fabiola, S. Krishnaswamy, V. Nagarajan, and V. Pattabhi, Acta Crystallogr., Sect. D: Biol. Crystallogr. D53, 316 (1997). 